\title{
Pengaruh Karakteristik Kewirausahaan terhadap Kinerja Usaha Mikro, Kecil dan Menengah (UMKM) Gula Aren di Kabupaten Lombok Barat
}

\section{The Effect of Entrepreneurial Characteristics towards The Business Performance of Palm Sugar Micro, Small and Medium Entreprises in West Lombok Regency}

\author{
Ni Made Wirastika Sari ${ }^{1}$, Heny K. Suwarsinah ${ }^{2}$, Lukman M. Baga ${ }^{2}$ \\ ${ }^{1)}$ Departemen Agribisnis, FEM, SPS IPB \\ ${ }^{2}$ Staf Pengajar Departemen Agribisnis, Fakultas Ekonomi Manajemen IPB
}

\begin{abstract}
Entrepreneurs are inovators and drivers of development. Entrepreneurs play an important role in improving national growth. The palm sugar MSMEs also absorbs much labor. This research aims analyze the effect of entreperenurial characteristics towards the business performance of palm sugar MSMEs in the West Lombok Regency. In this research, entrepreneurial characteristics consist of individual and psicological characteristics; whereas entrepreneurial competencies consist of managerial skill, conceptual skill, social skill, decision making skill and time managerial skill; finally, business performance indicators consist of profit and sales volume. This research used 120 data samples of palm sugar MSMEs that were collected through propotional cluster sampling in the West Lombok regency from June 2015 until August 2015. The data were analyzed by SEM analysis with LISREL 8,30 sofware. The result showed that both individual and psychological entrepreneurial characteristics significantly and positively influenced business performace. However, these characteristics also significantly and negatively influenced entrepreneurial competencies, which reduced the positive impact in business performance.
\end{abstract}

Keywords: Business performace, characteristics, entrepreneurial, micro small and medium enterprises (MSMEs), palm sugar

\section{Abstrak}

Wirausahawan adalah inovator dan penggerak pembangunan. Wirausahawan memiliki peranan penting dalam meningkatkan pembangunan suatu negara. Tujuan dari penelitian ini adalah menganalisis pengaruh karakteristik kewirausahaan terhadap kinerja usaha pada unit UMKM gula aren di Kabupaten Lombok Barat. Karakteristik kewirausahaan dalam penelitian ini dibedakan menjadi karakteristik individual dan karakteristik psikologis, selanjutnya kompetensi kewirausahaan dilihat dari inidkator kemampuan manajerial, kemampuan konseptual, kemampuan sosial, kemampuan membuat keputusan dan kemampuan mengatur waktu. Kinerja usaha dilihat dari indikator keuntungan dan volume penjualan. Penelitian ini di lakukan pada bulan Juni 2015 hingga bulan Agustus 2015 di Kabupaten Lombok Barat. Data yang digunakan diperoleh dari hasil wawancara menggunakan kuesioner. Jumlah sampel yang digunakan sebanyak 120 unit UMKM yang dipilih dengan teknik probability sampling secara cluster sampling. Analisis data dilakukan menggunakan metode SEM dengan bantuan software LISREL 8,30. Hasil penelitian menunjukkan bahwa karakteristik kewirausahaan berpengaruh secara nyata dan positif terhadap kompetensi kewirausahaan maupun kinerja usaha, namun karakteristik kewirausahaan berpengaruh negatif dan signifikan terhadap kinerja usaha melalui kompetensi kewirausahaan.

Kata kunci: Karakteristik, Kewirausahaan, kinerja usaha, usaha mikro kecil menengah (UMKM), gula aren

\section{Pendahuluan}

Usaha mikro, kecil dan menengah (UMKM) merupakan bagian dari usaha nasional yang berperan penting dalam mewujudkan tujuan pembangunan nasional. UMKM juga dapat dianggap sebagai lokomotif pertumbuhan ekonomi nasional dan regional (daerah), karena berpotensi dalam memberdayakan semua sumber daya yang ada dan mendorong tumbuhnya pengembangan kewirausahaan. Peranan UMKM di Indonesia yaitu (1) peningkatan kesempatan kerja, (2) pemerataan pendapatan, (3) pembangunan ekonomi pedesaan, (4) peningkatan ekspor nonmigas dan (5) berkontribusi terhadap peningkatan PDB (Tambunan, 2009).

Tambunan (2009) menyebutkan karakteristik UMKM di Indonesia yaitu (1) jumlahnya sangat banyak melebihi jumlah usaha besar dan tersebar 
diseluruh pelosok pedesaan, termasuk di wilayahwilayah yang relatif terisolasi, (2) UMKM sangat padat karya sehingga UMKM mempunyai potensi pertumbuhan kesempatan kerja yang sangat besar, (3) umumnya berbasis pertanian, (4) UMKM menggunakan teknologi-teknologi yang lebih sesuai terhadap proporsi faktor-faktor produksi dan kondisi lokal yang ada, dan (5) Tingkat fleksibilitas yang tinggi.

UMKM menyediakan kesempatan kerja yang sangat besar, sehingga UMKM di Indonesia memerlukan perhatian khusus agar dapat terus tumbuh dan mengembangkan usahanya. Pemerintah Indonesia menunjukkan perhatian dalam wujud nyata terhadap UMKM dengan mengeluarkan undang-undang nomor 20 tahun 2008 tentang usaha mikro, kecil dan menengah. Undang-undang ini menjabarkan kriteria usaha mikro, kecil dan menengah. Isi undang-undang ini menyebutkan bahwa pemerintah dan pemerintah daerah akan menumbuhkan iklim usaha dengan menetapkan peraturan perundang-undangan dan kebijakan yang meliputi aspek (1) pendanaan, (2) sarana dan prasarana, (3) informasi usaha, (4) kemitraan, (5) perijinan usaha, (6) kesempatan berusaha, (7) promosi dagang dan (8) dukungan kelembagaan, serta pemerintah akan memfasilitasi pengembangan usaha dalam bidang (1) produksi, (2) pemasaran, (3) sumberdaya manusia dan (4) desain dan teknologi.

UMKM di Indonesia banyak bergerak di sektor pertanian. Sektor pertanian berperan penting sebagai penyedia bahan pangan bagi masyarakat dan bahan baku bagi industri. Kewirausahaan menjadi solusi agar usaha di sektor pertanian dapat terus berjalan. UMKM gula aren dikelola dalam bentuk kluster atau sentra untuk meningkatkan daya saing produk dengan menekan biaya produksi dan biaya pemasaran gula aren. Gula aren yang dihasilkan diharapkan akan lebih kompetitif dipasaran dan memiliki daya saing lebih tinggi dibandingkan dengan produk sejenis (Kemenkop, 2008). Gula aren digunakan oleh masyarakat dan untuk bahan baku industri sebagai bahan pemanis makanan dan minuman. Gula aren diminati karena rasanya yang manis dan memiliki aroma yang khas, sehingga dapat menambah cita rasa bila ditambahkan dalam setiap minuman atau makanan. Keunggulan yang dimiliki gula aren membuat permintaan terhadap gula aren terus meningkat (Depperin, 2009). Salah satu wilayah di Indonesia yang merupakan sentra UMKM gula aren adalah Kabupaten Lombok Barat. Kabupaten Lombok Barat merupakan wilayah sentra UMKM gula aren di Provinsi Nusa Tenggara Barat. Jumlah UMKM gula aren di Kabupaten Lombok Barat sebanyak 282 unit. Jumlah tenaga kerja yang diserap sebanyak 614 orang dengan nilai produksi pada tahun 2013 mencapai 6456 milyar rupiah (Disperindag NTB, 2013).

Karakteristik kewirausahaan secara umum menggambarkan keunikan personal atau psikologis seseorang yang terdiri dari dimensi nilai sikap dan kebutuhan. Nurhayati et al., (2011) dalam penelitiannya berhasil menemukan bahwa karakteristik psikologis kewirausahaan berpengaruh secara nyata dan positif terhadap kompetensi kewirausahaan maupun kinerja usaha. Hal ini menujukan pentingnya membangun karakteristik kewirausahaan karena karakteristik kewirausahaan sangat menentukan keberhasilan usaha. Karakteristik kewirausahaan merupakan kunci untuk memaksimalkan efisiensi dari penggunaan faktor-faktor pengembangan daya saing ekonomi, memungkinkan UMKM memiliki pola pikir (mindset) yang lebih positif, membangun kesensitifan terhadap pasar dan penciptaan daya pikir kreatif. Oleh sebab itu penelitian mengenai pengaruh karakteristik kewirausahaan terhadap kinerja usaha pada UMKM gula aren di Kabupaten Lombok Barat dianggap penting untuk dilakukan. Permasalahan dalam penelitian ini yaitu bagaimana pengaruh karakteristik kewirausahaan terhadap kinerja usaha UMKM gula aren di Kabupaten Lombok Barat. Tujuan penelitian ini adalah menganalisis pengaruh karakteristik kewirausahaan terhadap kinerja usaha pada unit UMKM gula aren di Kabupaten Lombok Barat.

\section{Metode Penelitian}

Penelitian ini dilakukan di dua kecamatan di Kabupaten Lombok Barat yaitu Kecamatan Gunung sari dan Kecamatan Lingsar pada tiga desa berdasarkan pertimbangan bahwa pada ketiga desa tersebut terdapat UMKM dengan jumlah unit usaha, tenaga kerja, nilai investasi, kapasitas produksi dan nilai produksi terbesar di dua kecamatan yang menjadi lokasi penelitian. Penelitian ini dilakukan 
di Desa Kekait, Desa Karang bayan dan Desa Langko. Populasi dalam penelitian ini adalah 165 unit UMKM gula aren di Kabupaten Lombok Barat. Sampel dalam penelitian ini dipilih dengan teknik probability sampling secara cluster sampling di Kecamatan Gunung sari dan Kecamatan Lingsar di Kabupaten Lombok Barat karena kedua kecamatan ini memiliki jumlah UMKM gula aren sebanyak 165 UMKM, dan total jumlah sampel yang digunakan dalam penelitian ini sebanyak 120 unit UMKM gula aren. Jumlah sampel dalam penelitian ini dipilih dengan teknik probability sampling secara cluster sampling di Kabupaten Lombok Barat

Jumlah sampel sebanyak 120 unit UMKM gula aren dalam penelitian ini akan dianalisis secara kuantitatif menggunakan metode SEM. Penelitian ini menggunakan data primer dan data sekunder. Data primer diperoleh dari hasil wawancara dengan menggunakan kuesioner dan data sekunder diperoleh dari BPS NTB, Dinas Perindustrian dan Perdagangan NTB serta literatur lainnya yang dapat dijadikan bahan rujukan. Variabel yang digunakan dalam penelitian ini terdiri dari variabel laten dan variabel manifest (Tabel 1). Data dalam penelitian Tabel 1 Variabel laten dan indikator penelitian penelitian

\begin{tabular}{|c|c|c|c|}
\hline No & Variabel Laten & Variabel manifest /Indikator & Sumber Acuan \\
\hline 1 & $\begin{array}{l}\text { Karakteristik individu (KI) } \\
\text { (laten eksogen) }\end{array}$ & $\begin{array}{ll}\text { 1. } & \text { Usia }(\mathrm{X} 1.1) \\
\text { 2. } & \text { Pendidikan }(\mathrm{X} 1.2) \\
\text { 3. } & \text { Pengalaman }(\mathrm{X} 1.3) \\
\text { 4. } & \text { Kekosmopolitan }(\mathrm{X} 1.4)\end{array}$ & $\begin{array}{l}\text { Cason et al.,(2006); Muhara- } \\
\text { stri (2013); Sumantri (2013). }\end{array}$ \\
\hline 2 & $\begin{array}{l}\text { Karakteristik Psikologis(KP) } \\
\text { (laten eksogen) }\end{array}$ & $\begin{array}{ll}\text { 1. } & \text { Pekerja Keras }(\mathrm{X} 2.1) \\
\text { 2. } & \text { Percaya diri (X2.2) } \\
\text { 3. } & \text { Disiplin }(\mathrm{X} 2.3) \\
\text { 4. } & \text { Berani mengambil risiko }(\mathrm{X} 2.4) \\
\text { 5. } & \text { Toleransi terhadap ketidakpastian }(\mathrm{X} 2.5) \\
\text { 6. } & \text { Innovatif }(\mathrm{X} 2.6) \\
\text { 7. } & \text { Mandiri }(\mathrm{X} 2.7) \\
\text { 8. } & \text { Bertanggung jawab (X2.8) }\end{array}$ & $\begin{array}{l}\text { Kao (1991); Miner (1997); } \\
\text { Kuratko dan Hodgress (2007); } \\
\text { Basrowi (2011); Daniarti } \\
\text { (2012); Hasbullah dan } \\
\text { Sulaeman (2012); }\end{array}$ \\
\hline 3 & $\begin{array}{l}\text { Kompetensi Kewirausahaan } \\
\text { (KK) } \\
\text { (laten endogen) }\end{array}$ & $\begin{array}{ll}\text { 1. } & \text { Kemampuan manajerial (Y1.1) } \\
\text { 2. } & \text { Kemampuan konseptual (Y1.2) } \\
\text { 3. } & \text { Kemampuan sosial (Y1.3) } \\
\text { 4. } & \text { Kemampuan membuat keputusan (Y1.4) } \\
\text { 5. } & \text { Kemampuan mengatur waktu (Y1.5) }\end{array}$ & $\begin{array}{l}\text { Suryana (2003); Moeheriono } \\
\text { (2009); Nurhayati et al., } \\
\text { (2011); Isa (2013). }\end{array}$ \\
\hline 4 & $\begin{array}{l}\text { Kinerja Usaha (KU) } \\
\text { (laten endogen) }\end{array}$ & $\begin{array}{l}\text { Keuntungan (Y2.1) } \\
\text { Volume penjualan (Y2.2) }\end{array}$ & $\begin{array}{l}\text { Venkatraman dan Rajamunjam } \\
\text { (1986); Kuratko dan Hodgerss } \\
\text { (2007); Muharastri (2013). }\end{array}$ \\
\hline
\end{tabular}

ini dianalisis dengan metode SEM (Structural Equation Model) dengan program LISREL 8,30. Tahapan prosedur SEM diawali dengan tabulasi data hasil pengisisan kuesioner dengan menggunakan MS Exel 2007, kemudian di analisis dengan metode SEM dengan tahapan (1) spesifikasi model; (2) identifikasi model; (3) estimasi model; (4) uji validitas dan reliabilitas; (5) uji kecocokan model dan (6) respesifikasi model.

\section{Uji validitas dan reliabiltas}

Validitas model pengukuran dilihat berdasarkan estimasi $t$-value. Jika suatu variabel manifest/ indikator memiliki nilai t-value $<1,96$, maka variabel manifest/indikator tersebut tidak signifikan dan dapat dihapuskan dari model. Hasil analisis model pengukuran menun jukkan bahwa variabel manifest/ indikator pengalaman (X1.3) dengan nilai t-value 1,26 tidak signifikan hubungannya dengan tiga manifest/indikator lainnya dalam merepresentasikan karakteristik individu dan indikator tersebut dapat dihapuskan dalam model.

Reliabilitas konstruk pembentuk model pengukuran dianalisis dengan menggunakan kriteria 
Tabel 2 Pengujian reliabilitas model pengukuran

\begin{tabular}{llll}
\hline Variabel laten & CR & $\begin{array}{l}\text { Reli- } \\
\text { abili- } \\
\text { tas }\end{array}$ & $\begin{array}{l}\text { VE } \\
\text { Reli- } \\
\text { abili- } \\
\text { tas }\end{array}$ \\
\hline $\begin{array}{l}\text { Karakteristik } \\
\text { individu(KI) }\end{array}$ & $\begin{array}{l}0,91 \geq \text { Baik } \\
0,70\end{array}$ & $\begin{array}{l}0,82 \geq \\
0,50\end{array}$ \\
$\begin{array}{l}\text { Karakteristik } \\
\text { psikologis(KP) }\end{array}$ & $\begin{array}{l}0,87 \geq \text { Baik } \\
0,70\end{array}$ & $\begin{array}{l}0,46 \leq \\
0,50 \quad \text { Cuk- }\end{array}$ \\
Kompetensi ke- & $0,93 \geq$ Baik & $\begin{array}{l}0,81 \geq \text { Baik } \\
\text { wirausahan(KK) } \\
0,70\end{array}$ & 0,50 \\
Kinerja usa- & $0,81 \geq$ Baik & $0,69 \geq$ Baik \\
ha(KU) & 0,70 & 0,50
\end{tabular}

construct reliability $(\mathrm{CR}) \geq 0,70$ dan variance extracted $(\mathrm{VE}) \geq 0,50$. Berdasarkan pengujian reliabilitas model pengukuran, pengujian reliabilitas model pengukuran (Tabel 2), seluruh variabel laten memiliki nilai CR dan VE yang mendukung reliabitas yang baik. Nilai CR dan VE yang baik menunjukkan bahwa indikator-indikator yang digunakan dalam penelitian memiliki kekonsistenan tinggi, sehingga jika dilakukan penelitian ulang pada waktu yang berbeda, responden wirausahawan UMKM agroindustri gula aren di Kabupaten Lombok Barat akan memberikan jawaban yang reliabel/konsisten.

\section{Uji kecocokan model}

Uji kecocokan keseluruhan model dilakukan untuk mengevaluasi secara umum derajat kecocokan (goodness of fit). Uji kecocokan model dengan SEM tidak dapat ditentukan hanya dengan satu kriteria kesesuaian. Hasil kesesuaian model persamaan struktural dapat dilihat nilai hasil uji RMSEA (Root Mean square Error of Approximation) model untuk mengetahui rata-rata perbedaan per degree of freedom yang diharapkan terjadi dalam populasi dan bukan pada sampel.

Nilai RMSEA $\leq 0,05$ menandakan close fit, sedangkan 0,05 < RMSEA $\leq 0,08$ menujukan good fit (Brown dan Cuedeck, 1993) dan Mc Callum (1996) menambahkan bahwa nilai RMSEA antara 0,08 sampai 0,10 menujukan marginal fit. Nilai RMSEA dalam penelitian ini sebesar 0,081 mengindikasikan model cukup baik (marginal fit).

Nilai GFI(Goodness of Fit Index) merupakan suatu ukuran yang menunjukkan seberapa besar

Tabel 3 Hasil kesesuaian model persamaan struktural berdasarkan ukuran kecocokan absolut

\begin{tabular}{|c|c|c|c|}
\hline Ukuran Goodness of Fit (GOF) & $\begin{array}{l}\text { Tingkat kecocokan yang } \\
\text { bisa diterima }\end{array}$ & Hasil & Keterangan \\
\hline \multirow[t]{2}{*}{ RMSEA (Root Mean Square Error of Approximation) } & $\begin{array}{l}\text { RMSEA } \leq 0,08 \text { RMSEA } \\
\text { good fit }\end{array}$ & 0,081 & Marginal fit \\
\hline & $\begin{array}{l}\text { RMSEA }<0,05 \text { adalah close } \\
\text { fit. }\end{array}$ & & \\
\hline GFI (Goodness of Fit Index) & $\begin{array}{l}\text { GFI } \geq 0,90 \text { good fit, se- } \\
\text { dangkan } 0,80 \leq \mathrm{GFI}<0,90 \\
\text { marginal fit. }\end{array}$ & 0,92 & Good fit \\
\hline RMR (Root Mean Square Residual) & $\mathrm{RMR} \leq 0,05$ adalah good fit. & 0,12 & Poor fit \\
\hline NFI (Normed Fit Index) & $\begin{array}{l}\text { NFI } \geq 0,90 \text { good fit, se- } \\
\text { dangkan } 0,80 \leq \mathrm{NFI}<0,90 \\
\text { marginal fit. }\end{array}$ & 0,86 & Marginal fit \\
\hline AGFI (Adjusted Goodness of Fit Index) & $\begin{array}{l}\text { AGFI } \geq 0,90 \text { good fit }, \\
\text { sedangkan } 0,80 \leq \text { AGFI }< \\
0,90 \text { marginal fit. }\end{array}$ & 0,88 & Marginal fit \\
\hline AIC (Akaike Information Criterion) & $\begin{array}{l}\text { Nilai positif lebih kecil } \\
\text { menunjukkan parsimoni } \\
\text { lebih baik, dekat dengan } \\
\text { AIC saturated }\end{array}$ & 346,56 & Good fit \\
\hline CAIC (Consistent Akaike Information Criterion) & $\begin{array}{l}\text { Nilai positif lebih kecil } \\
\text { menunjukkan parsimoni leb- } \\
\text { ih baik., dekat dengan CAIC } \\
\text { saturated }\end{array}$ & 573,02 & Good fit \\
\hline
\end{tabular}


model mampu menerangkan keragaman data. Nilai GFI model telah sesuai dengan kriteria baik (good fit) dengan nilai sebesar 0,91. Nilai hasil uji RMR (Root Mean Square Residuan) adalah rata-rata antara matrik teramati dan hasil estimasi. Nilai RMR dalam penelitian ini sebesar 0,12 ini menunjukkan kurang baik (poor fit). Nilai NFI (Normed Fit Index) model sebesar 0,84 termasuk dalam kategori cukup baik (marginal fit). Nilai AGFI (Adujusted Goodness-offit Index) adalah perluasan dari GFI yang disesuaikan dengan rasio antara degree of freedom dari null/ independence model dengan degree of freedom dari model yang dihipotesiskan atau diestimasi (Joreskog dan Sorbom 1989). Nilai AGFI dalam model ini sebesar 0,87 ini menujukan cukup baik (marginal fit). Nilai AIC (Akaike Information Criterion) model sebesar 386,55 menunjukkan kategori baik (good fit) dan nilai CAIC (Consistent Akaike Information Criterion) model menunjukkan kategori baik (good fit). Berdasarkan tujuh ukuran uji kecocokan model, satu kriteria menunjukkan hasil kurang baik (poor fit), tiga kriteria menunjukkan hasil cukup baik (marginal fit) dan tiga kriteria menunjukkan hasil baik (good fit) dengan data yang ada maka dapat ditarik kesimpulan bahwa model dalam penelitian ini relatif memiliki tingkat kecocokan yang baik (good fit) (Tabel 3).

\section{Hasil dan Pembahasan}

\section{Karakteristik Responden}

Responden dalam penelitian ini berjumlah 120 orang. Dari 120 orang tersebut, terdapat beberapa karakteristik yang menonjol yaitu jenis kelamin didominasi oleh laki-laki $(96,67 \%)$, usia responden terbanyak berada pada rentang usia 40-49 tahun $(39,17 \%)$ dan tingkat pendidikan terbanyak hingga setingkat SD (74.17\%). Hal ini menunjukkan tingkat pendidikan responden termasuk kategori rendah. Tingkat pendidikan yang rendah menggambarkan tingkat kemajuan dan kemampuan sumber daya manusia yang relatif rendah. Wirausaha yang pernah mengikuti pelatihan hanya $0.83 \%$. Hal ini menujukkan masih kurangnya perhatian pemerintah terhadap wirausaha UMKM gula aren di Kabupaten Lombok Barat dengan cara memberikan pelatihanpelatihan yang dapat menunjang kompetensi wirausaha untuk meningkatkan kinerja usahanya.
UMKM gula aren di Kabupaten Lombok Barat paling banyak dikelola dalam skala usaha mikro (98.33\%). UMKM dijalankan tanpa menggunakan tenaga kerja (98.33\%) karena usaha yang dijalankan dalam skala usaha mikro dengan kapasitas produksi kecil. Responden dalam penelitian ini telah menjalankan usaha selama 11-15 tahun (38.33\%). Hal ini menunjukkan responden telah berpengalaman dalam menjalankan UMKM gula aren, baik dari proses pembuatan gula aren hingga pemasaran gula aren. Wirausaha gula aren di Kabupaten Lombok Barat yang menjadi responden dalam penelitian ini seluruhnya $(100 \%)$ memulai usaha dengan modal sendiri. Hal ini menunjukkan bahwa responden dalam penelitian ini mandiri dalam menjalankan usahanya dan tidak ingin terikat dengan lembaga pembiayaan atau pihak lain.

\section{Analisis Pengaruh Karakteristik Kewirausahaan terhadap Kinerja Usaha}

Analisis SEM dalam penelitian ini dilakukan dengan pendekatan one step, yaitu dengan membentuk model SEM full/hybrid. Model SEM full/hybrid yaitu gabungan antara dua model pengukuran dan model struktural. Gabungan model pengukuran dan model struktural diestimasi secara simultan dalam sebuah analisis tunggal. Hal ini sesuai dengan tujuan penelitian, yaitu menganalisis pengaruh karakteristik kewirausahaan terhadap kinerja UMKM gula aren di Kabupaten Lombok Barat.

Model pengukuran menunjukkan hubungan antara variabel laten dengan variabel manifest/

Tabel 4 Hubungan antar variabel laten

\begin{tabular}{llll}
\hline \multicolumn{1}{c}{ Hubungan antar variabel laten } & \multicolumn{1}{c}{$\begin{array}{c}\text { Muatan } \\
\text { faktor }(\gamma, \boldsymbol{\beta})\end{array}$} & t-value \\
\hline $\begin{array}{l}\text { Karakteristik } \\
\text { individu (KI) }\end{array}$ & $\begin{array}{l}\text { Kompetensi } \\
\text { kewirausahaan } \\
(\mathrm{KK})\end{array}$ & 0,06 & $2,23^{*}$ \\
& $\begin{array}{l}\text { Kompetensi } \\
\text { Karakteristik } \\
\text { psikologis (KP) }\end{array}$ & $\begin{array}{l}\text { kewirausahaan } \\
(\mathrm{KK})\end{array}$ & $15,34^{*}$ \\
$\begin{array}{l}\text { Karakteristik } \\
\text { individu (KI) }\end{array}$ & $\begin{array}{l}\text { Kinerja usaha } \\
\text { KU) }\end{array}$ & 0,10 & $2,66^{*}$ \\
$\begin{array}{l}\text { Karakteristik } \\
\text { psikologis (KP) }\end{array}$ & $\begin{array}{l}\text { Kinerja usaha } \\
\text { KU) }\end{array}$ & 0,27 & $3,01^{*}$ \\
Kompetensi & $\begin{array}{l}\text { Kinerja usaha } \\
(\mathrm{KU})\end{array}$ & $-0,20$ & $-1,90$ \\
\hline Keterangan $*$ * & & \\
\hline
\end{tabular}

Keterangan : *signifikan pada taraf 5\% 


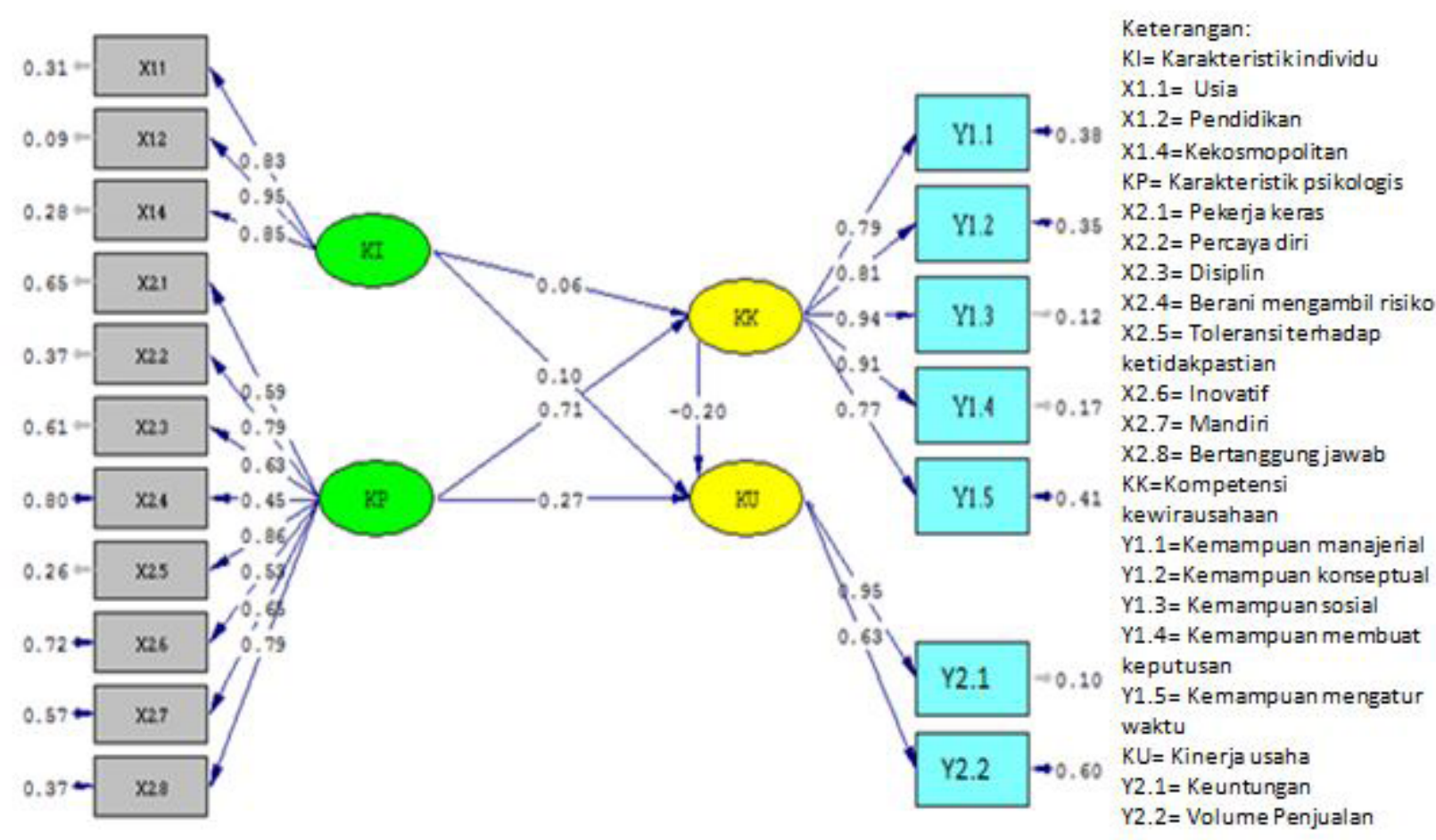

Ch1-Square $=231.56, d f=131, p$-value $=0.00000$, RUSEA $=0.080$

Gambar 1 Diagram lintas model SEM berdasarkan estimasi T-value (setelah direspesifikasi)

\section{indikatornva dan seberapa kuat variabel}

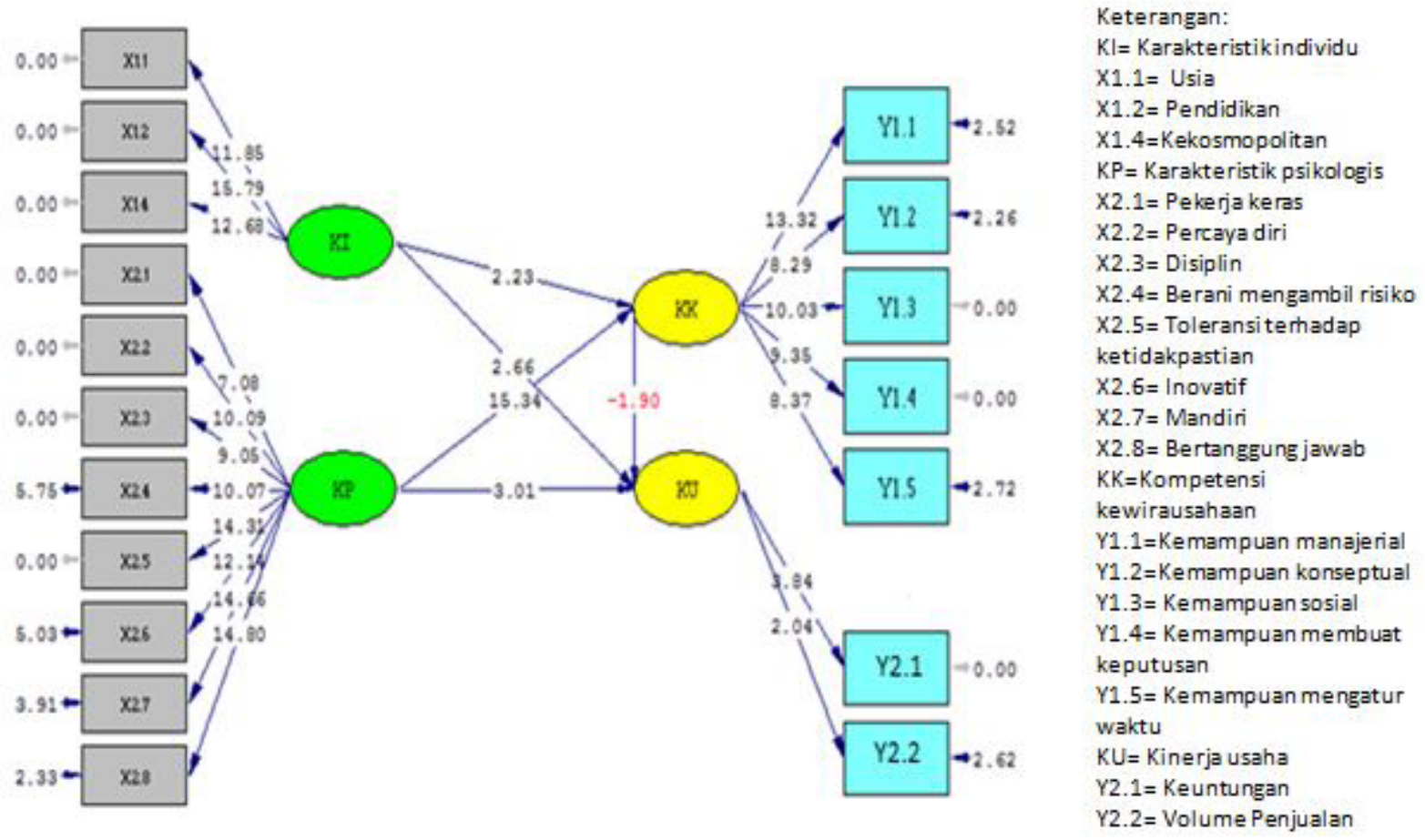

Ch1-Square $=231.56$, df $=131$, p-value $=0.00000$, RusEA $=0.080$

Gambar 2 Diagram lintas model SEM berdasarkan estimasi Standardized Solution (setelah direspesifikasi) 
manifest/indikator dalam mengukur setiap variabel latennya. Model struktural menunjukkan pengaruh variabel laten eksogen (karakteristik kewirausahaan) terhadap laten endogen (kompetensi kewiraushaan dan kinerja usaha). Hubungan tersebut digambarkan dalam path diagram. Nilai loading factor digunakan untuk mengukur besarnya kemampuan variabel manifest/indikator dalam model SEM dan untuk mengukur keeratan hubungan antar variabel laten dalam model SEM dengan estimasi standardized solution.

Nilai loading factor berdasarkan hasil estimasi standardized solution (Gambar 1) dan nilai loading factor berdasarkan hasil estimasi t-value (Gambar 2) yang dirangkum dalam Tabel 4 menunjukkan dari lima hubungan yang dianalisis terdapat empat hubungan yang siginifikan dan satu hubungan yang tidak signifikan. Hal ini berarti tinggi rendahnya kinerja usaha wirausahawan dari UMKM gula aren di Kabupaten Lombok Barat tidak dipengaruhi oleh kompetensi kewirausahaan (KK). Nilai muatan faktor hubungan antara kompetensi kewirausahan (KK) dengan kinerja usaha (KU) bernilai negatif, diartikan adanya penurunan manfaat terhadap kinerja usaha terhadap UMKM gula aren akibat adanya kompetensi kewirausahaan.

Kinerja usaha pada UMKM gula aren di Kabupaten Lombok Barat secara signifikan dipengaruhi oleh karakteristik individu dengan nilai muatan faktor yang positif $(\beta=0,10)$ dan karakteristik psikologis dengan nilai muatan faktor yang positif $(\beta=0,27)$. Nilai muatan faktor hubungan karakteristik psikologis terhadap kinerja usaha lebih besar dan bernilai positif. Hal ini menunjukkan karakteristik psikologis lebih kuat mempengaruhi kinerja usaha.

Kompetensi kewirausahaan pada UMKM gula aren di Kabupaten Lombok Barat secara signifikan dipengaruhi oleh karakteristik individu dengan nilai muatan faktor yang positif $(\gamma=0,06)$ dan karakteristik psikologis dengan nilai muatan faktor yang positif $(\gamma=0,71)$ (Tabel 5). Nilai muatan faktor hubungan karakteristik psikologis terhadap kompetensi kewirausahaan lebih besar dan bernilai positif. Hal ini menunjukkan karakteristik psikologis lebih kuat mempengaruhi kompetensi kewirausahaan.

Tabel 5 Koefisien pengaruh dan signifikansi variabel karakteristik kewirausahaan, kompetensi kewirausahaan dan kinerja usaha (setelah direspesifikasi)

\begin{tabular}{|c|c|c|c|}
\hline Indikator /indikator & Variabel laten & Loading Factor & T-Hitung \\
\hline Usia (X1.1) & Karakterisitik & 0,83 & $11,79 *$ \\
\hline Pendidikan (X1.2) & \multirow{4}{*}{ individu } & 0,96 & $15,47 *$ \\
\hline Kekosmopolitan (X1.4) & & 0,85 & $12,69^{*}$ \\
\hline Pekerja keras (X2.1) & & 0,59 & $6,96^{*}$ \\
\hline Percaya diri (X2.2) & & 0,80 & $10,13^{*}$ \\
\hline Displin (X2.3) & \multirow[b]{2}{*}{ Karaktersitik } & 0,63 & $9,05 *$ \\
\hline Berani mengambil risiko (X2.4) & & 0,45 & $9,89 *$ \\
\hline Toleransi terhadap ketidakpastian (X2.5) & \multirow{5}{*}{ Psikologis } & 0,86 & $14,24 *$ \\
\hline Innovatif (X2.6) & & 0,53 & $11,61^{*}$ \\
\hline Mandiri (X2.7) & & 0,65 & $14,88^{*}$ \\
\hline Bertanggung jawab (X2.8) & & 0,79 & $15,16^{*}$ \\
\hline Kemampuan manajerial (Y1.1) & & 0,79 & $13,52 *$ \\
\hline Kemampuan konseptual (Y1.2) & \multirow{4}{*}{$\begin{array}{l}\text { Kompetensi } \\
\text { kewirausahaan }\end{array}$} & 0,81 & $8,36^{*}$ \\
\hline Kemampuan sosial (Y1.3) & & 0,94 & $10,15^{*}$ \\
\hline Kemampuan membuat keputusan (Y1.4) & & 0,91 & $9,41 *$ \\
\hline Kemampuan mengatur waktu (Y1.5) & & 0,76 & $8,48 *$ \\
\hline Keuntungan (Y2.2) & \multirow{2}{*}{ Kinerja usaha } & 0,95 & $3,77 *$ \\
\hline Volume penjualan (Y2.3) & & 0,63 & $1,99 *$ \\
\hline
\end{tabular}


Koefisien hasil estimasi model menunjukkan hubungan antar variabel yang diinterpretasikan untuk menggambarkan keeratan hubungan antar variabel. Jika nilai $\mathrm{T}$ hitung $>\mathrm{T}$ Tabel dengan taraf 5 persen $(\mathrm{T}$ Tabel $=1,96)$, artinya suatu variabel berpengaruh nyata atau signifikan terhadap variabel lainnya.

Kontributor terbesar untuk variabel laten karakteristik individu adalah variabel manifest pendidikan (X1.2) dengan nilai loading factor sebesar $\lambda=0,96$. Tingkat pendidikan dalam penelitian ini dilihat dari persepsi tertinggi responden pada pernyataan seorang pengusaha harus bisa membaca dan menulis. Pengusaha yang mampu membaca dan menulis dapat lebih mudah memperoleh informasi untuk meningkatkan usahanya dengan banyak membaca. Kemampuan menulis berguna untuk pengusaha dalam menulis catatan keuangan sederhana dalam menjalankan usaha yang dimiliki.

Variabel manifest karakteristik psikologis seluruhnya signifikan berpengaruh terhadap karaktersitik psikologis dan keseluruhan dan signifikan berpengaruh terhadap variabel laten kinerja usaha. Kontributor terbesar untuk variabel laten karakteristik psikologis adalah variabel manifest toleransi terhadap ketidakpastian (X2.5) dengan nilai loading factor sebesar $\lambda=0,86$. Toleransi terhadap ketidakpastian dalam penelitian ini dilihat dari persepsi tertinggi responden pada pernyataan ciri pengusaha sukses adalah yang mampu beradaptasi dengan situasi sulit. Ketidakpastian merupakan sesuatu yang tidak bisa diprediksi terjadinya. Seorang pengusaha dalam menjalankan usahannya selalu dekat dengan ketidakpastian. Pengusaha yang sukses adalah yang mampu bertahan, tidak mudah menyerah dan mampu beradaptasi menghadapi situasi sulit dengan melakukan perubahan-perubahan dalam usahanya.

Kompetensi kewirausahaan mencerminkan pengetahuan, kemampuan, keterampilan yang relatif dapat dipelajari dan ditingkatkan serta relatif dapat lebih mudah diamati. Kontributor terbesar untuk variabel laten kompetensi kewirausahaan adalah variabel manifest kemampuan sosial dengan nilai loading factor sebesar $\lambda=0,94$. Kemampuan sosial dalam penelitian ini dilihat dari persepsi tertinggi responden pada pernyataan ciri seorang wirausaha sukses yaitu seseorang yang berkonsultasi dengan pengusaha lain bila menghadapi masalah dalam bisnisnya. Wirausaha dengan kemampuan sosial yang tinggi mampu berkomunikasi dengan sesama wirausaha UMKM gula aren untuk saling bertukar pikiran dan pengalaman dalam menjalankan usaha. Kemampuan sosial yang tinggi juga dapat meningkatkan hubungan baik wirausaha dengan wirausaha lain dan pembeli, sehingga dapat memperluas jaringan pertemanan wirausaha.

Kinerja usaha merupakan suatu ukuran usaha yang dijalankan oleh wirausaha berhasil atau sukses. Kinerja usaha terdiri dari variabel manifest keuntungan (Y2.1) dan volume penjualan (Y2.2) dan keduanya berpengaruh terhadap kinerja usaha. Hal ini sesuai dengan pendapat Amstrong (2004) yang menyatakan bahwa kinerja usaha dapat diukur menggunakan indikator peningkatan keuntungan dan penjualan. Variabel manifest keuntungan berkontribusi paling besar terhadap kinerja usaha $(\lambda=0,95)$. Keuntungan dalam penelitian ini dilihat dari persepsi tertinggi responden terhadap pernyataan bahwa keuntungan bulan ini meningkat dibandingkan bulan lalu. Responden berpendapat seperti itu karena saat penelitian dilakukan bertepatan dengan bulan puasa. Saat bulan puasa terjadi peningkatan permintaan gula aren oleh masyarakat untuk membuat berbagai makanan serta minuman berbahan dasar gula aren. Peningkatan permintaan ini tidak didukung dengan peningkatan bahan baku untuk membuat gula aren, sehingga wirausaha tidak dapat meningkatkan jumlah gula aren yang diproduksi. Peningkatan permintaan gula aren yang tidak didukung dengan ketersediaan pasokan gula aren dalam jumlah yang cukup untuk memenuhi seluruh permintaan pasar menyebabkan wirausaha mengambil kesempatan dengan menaikan harga untuk meningkatkan keuntungan usahanya.

\section{Kesimpulan}

Karakteristik kewirausahaan UMKM gula aren di Kabupaten Lombok Barat dibedakan menjadi karakteristik individu dan karakteristik psikologis. Karakteristik kewirausahaan baik itu karaktersitik individu maupunkarakteristikpsikologis berpengaruh positif dan signifikan terhadap kinerja usaha. Hal ini menunjukkan pentingnya untuk membangun karakteristik kewirausahaan karena karakteristik kewirausahaan menentukan keberhasilan usaha. 


\section{Daftar Pustaka}

[BPS] Badan Pusat Statistik NTB. 2013. Pertumbuhan PDB UMKM 2009-2012. NTB (ID): BPS.

[Depperin] Departemen Perindustrian Jakarta. 2009. Roadmap Industri Gula. Jakarta (ID): Departemen Perindustrian.

[Kemenkop] Kementrian Koperasi dan UMKM. 2008. Kajian Efektifitas Model Pertumbuhan Klaster Bisnis UMKM Berbasis Agribisnis. Jakarta (ID): Kementrian Koperasi dan UMKM

Amstrong M. 2004. Performance Management. Yogyakarta (ID): Tugu Publisher.

Basrowi. 2011. Kewirausahaan Untuk Perguruan Tinggi. Bogor (ID): Ghalia Indonesia.

Bloodgood JM, Spienza HJ., Carsrud A. 1995. The Dynamics of New Business Start-us. Connecticut (US): Jurnal Agribisnis Indonesia Press.

Cassons M. 2006. The Oxford Handbook of Entrepreneurship. New York (NY): Oxford University Press.

Chamorro TP. 2005. Personality and Intellectual Competence. New Jersey (US): Lawrence Erlbaum Associates.

Danarti. 2012. Analisis Potensi dan Kebutuhan Pengembangan Kewirausahaan di Pusat KTM Telang. Jakarta (ID): Kementrian Tenaga Kerja dan Transmigrasi.

Darya P. 2012. Pengaruh Ketidakpastian Lingkungan dan Karakteristik Kewirausahaan terhadap Kompetensi Usaha dan Kinerja Usaha Mikro Kecil di Kota Balikpapan. Balikpapan (ID): Jurnal Inovasi dan Kewirausahaan.

Daryanto A. 2004. Keunggulan Daya Saing dan Teknik Identifikasi Komoditas Unggulan dalam Mengembangkan Potensi Ekonomi Regional. Bogor (ID): AGRIMEDIA. Manajemen Bisnis IPB 2(9).

Goethner MM, Obschonka RK., Silbereinsen, and Cantner U. 2012. Scientist transition to academic entrepreneurship: Economic and psychological determinants. Inggris (GB): Journal of Economic Psychology.

Hasbullah R, Sulaeman E. 2012. Pembinaan Karakter Wirausaha Mahasiswa Melalui Metode Pelatihan Soft skill di Fakultas Ekonomi Uniska. Banjarmasin (ID): Jurnal Manajemen.

Henderson J. 2002. Building The Rural Economy with high-growth Entrepreneurs. Economic Review-Federal Reserve Bank of Kansas City 87 (3).

Hofstede G. 1991. Culture and Organizations : Software of the mind. New York (US): McGraw Hill.

Isa M. 2013. Analisis Kompetensi Kewirausahaan, orinetasi Kewirausahaan, Dan Kinerja Industri Mebel. Surakarta (ID): BENEFIT Jurnal Manajamen dan Bisnis.

Kao. 1991. The Entrepreneur. USA (US): Harvad business School.

Kaur G dan Singh S. 2013. Women Entrepreneurs in India (IN): Problems and Prospects. Journal of Humanities and Social Science 1(1).

Kirzner IM.1978. Competition and Entrepreneurship. Chicago (US): Chicago University Press.

Krisnamurthi B. 2001. Agribisnis. Bogor (ID): Yayasan Pengembangan Sinar Tani

Kuratko FD, Hogetts MR. 2007. Entrepreneurship: Theory, Process and Practice. Canada (US): Thomson South-Western.

Kustiari T, Sumiardjo, Slamet M, Tjitropranoto. 2012. Pengaruh Efektifitas Penyuluhan Terhadap kompetensi Pembudidaya Rumput laut Polikultur di Perairan Pantai Utara Pulau Jawa. Bogor (ID): Jurnal Sosek Kelautan dan Perikanan.

Mappigau DP. 2012. Entreprenurial Quality of Smale Scale (SMEs) Broiler Farming with Independent Bussiness Model In Maros District of South Sulawesi Provincy, Indonesia (ID): Hasanuddin University.

Moeheriono. 2009. Pengukuran Kinerja Berbasis Kompetensi. Jakarta (ID): Ghalia Indonesia. 
Muatif K, Sugihen BG, Susanto D, Asngari PS. 2008. Kompetensi kewirausahaan peternak sapi perah, kasus peternak sapi perah di Kabupaten Bandung Jawa Barat. Bandung (ID): Jurnal Penyuluhan.

Muharastri Y. 2013. Karakteristik Wirausaha, Kompetensi Kewirausahaan dan Kinerja Usaha Peternakan Sapi Perah di KTTSP Kania Bogor. [tesis]. Bogor (ID): Institut Pertanian Bogor.

Nurhayati P, Heny KS., Tintin S., Yanti NM. 2012. Analisis Pengaruh Karakteristik Kewirausahaan terhadap Kinerja Wirausaha pada Unit Usaha Kecil-Menengah (UMKM) di Provinsi Jawa Barat. Bogor (ID): Prosiding Seminar Hasil Penelitian Institut Pertanian Bogor.

Nurhayati P, Tintin S., Heny KS., Yanti NM. 2011. Analisis Pengaruh Karakteristik Kewirausahaan terhadap Kinerja Wirausaha pada Unit Usaha Kecil Menengah (UMKM) Agroindustri Di Kabupaten Bogor. Bogor (ID): Prosiding Seminar Unggulan Departemen Agribisnis.

Nurhayati P. 2011. Karakteristik dan Kinerja Wirausaha Wanita pada UMKM Agroindustri Perikanan di Kabupaten Sukabumi. Bogor (ID): Prosiding Seminar Hasil Penelitian Institut Pertanian Bogor.

Pamela. 2013. "Kompetensi Kewirausahaan dengan Keberhasilan Usaha Peternak Sapi Perah Pujon, Malang”.[tesis]. Bogor (ID): Sekolah Pascasarjana Institut Pertanian Bogor.

Praag CM. 2005. Successful Entrepreneurship. United Kingdom (UK): Edward Elgar Publishing Limited.

Purwati E. 2012. Pengaruh Karakteristik Wirausaha, Modal Usaha, Strategi Pemasarana terhadap Perkembangan UMKM Di desa Dayaan dan Kalillondo Salatiga. Salatiga (ID): Jurnal Ilmiah Among Makarti 9(5).

Puspitasari. 2013. Pengaruh Perilaku Kewirausahaan Petani Anggrek terhadap Kinerja Usaha: Kasus di Kecamatan Gunung Sindur dan Parung, Kabupaten Bogor, dan Kecamatan Serpong,
Kota Tangerang Selatan [Tesis]. Bogor (ID): Sekolah Pascasarjana Institut Pertanian Bogor.

Richards ST, S.L. Bulkley. 2007. Agricultural entrepreneurs: the first and the forgotten? New York (GB): The Hudson Institute, Center for Employment Policy.

Robbins L. 1932. The Nature and Significance of Economic Science. London (GB): Macmillan.

Saragih B. 2010. Suara Agribisnis: Kumpulan Pemikiran Bungaran Saragih. Jakarta (ID): PT Permata Wacana Lestari.

Schumpeter JS. 1934. The Theory of Economic Development. Inggris (GB): Oxford Univercity press.

Sekaran U. 2000. Research Methods for Business. 3rd ed. New York (NY): John Wiley \& Sons.

Snell SA, Kenneth NW. 2002. Mengenali Penyebab-Penyebab Kinerja Buruk. Jakarta (ID): PT Elex Media Kompotindo.

Sumantri B. 2013. Pengaruh Jiwa Kewirausahaan terhadap Kinerja Usaha Wirausaha Wanita pada Industri Pangan Rumahan di Bogor. [tesis]. Bogor (ID): Sekolah Pascasarjana Institut Pertanian Bogor.

Suryana. 2003. Kewirausahaan: Pedoman Praktis Kiat dan Proses Menuju Sukses. Jakarta (ID): Salemba Empat.

Tambunan TTH. 2009. UMKM di Indonesia. Bogor (ID): Ghalia Indonesia.

Venkatraman N, Ramanujam V. 1986. Measurement of Business Economic Performance An Examination of Method Convergence. Inggris (GB): Cambrige.

Wijanto SH. 2008. Structural Equation Modelling dengan LISREL 8.30. Yogyakarta (ID): Graha Ilmu.

Wu WW. 2009. A competency based model for the success of entrepreneurial start up. Jurnal WSEAs transactions on business and economics. 